\title{
Similaridade genética entre cultivares de cebola de diferentes tipos e origens, baseada em marcadores AFLP
}

\author{
Carlos Antonio F Santos'; Valter R Oliveira²; Marciene A Rodrigues'; Hugo Leonardo C Ribeiro ${ }^{1}$; \\ Giovani O Silva ${ }^{3}$ \\ ${ }^{1}$ Embrapa Semi-Árido, C. Postal 23, 56302-970 Petrolina-PE; ${ }^{2}$ Embrapa Hortaliças, C. Postal 218, 70351-970 Brasília-DF; ${ }^{3}$ Embrapa \\ Canoinhas, C. Postal 317, 84460-000 Canoinhas-SC; casantos@cpatsa.embrapa.br; valter@cnph.embrapa.br; marciene.rodrigues@cpatsa. \\ embrapa.br; hugo.ribeiro@cpatsa.embrapa.br; giovaniolegario@gmail.com
}

\begin{abstract}
RESUMO
Foi estimada a similaridade genética entre cultivares de cebola de diferentes tipos e regiões geográficas, de forma a orientar programas de recursos genéticos e melhoramento da espécie no Nordeste brasileiro. Foram analisadas 41 cultivares, adotando-se para a visualização da similaridade genética o fenograma UPGMA gerado da matriz de distâncias genéticas estimadas pelo coeficiente de Jaccard e baseadas em 146 bandas polimórficas de Pst 1 e Mse 1 de AFLP. A correlação cofenética foi de 0,91 , indicando boa confiabilidade da representação gráfica para a interpretação dos resultados. Foram observados dois grupos principais no fenograma, no ponto de corte de 0,55 de similaridade: 1) grupo formado por cultivares predominantemente brasileiras, com algumas inclusões de cultivares estrangeiras; e 2) grupo formado por três cultivares estrangeiras (Mercedes, Perfect e TEG 502 PRR). Rijnsburger Jumbo e IPA 8 apresentaram a maior similaridade (85\%), enquanto Madrugada foi a mais divergente em relação às demais cultivares. As cultivares da série IPA se dividiram em subgrupos no grupo das cultivares brasileiras (IPA 8, IPA 10 e IPA 11; IPA 12, IPA 7, IPA 2 e IPA 6; IPA 3, IPA 4 e IPA 9), indicando haver variabilidade genética a ser explorada entre aquelas situadas em subgrupos distintos. Bola Precoce e BRS Cascata apresentaram a maior similaridade entre as cultivares de origem brasileira. Foi observada similaridade superior a $39 \%$, refletindo a alta variabilidade genética da coleção de cebola estudada. A introdução de novos acessos deve considerar procedências outras que não norte americanas, para aumentar a variabilidade de germoplasma de cebola disponível no Nordeste do Brasil.
\end{abstract}

Palavras-chave: Allium cepa, cultivares, dissimilaridade, índice de Jaccard, UPGMA.

\begin{abstract}
Genetic similarity among onion cultivars of different types and origins, based on AFLP markers

The genetic similarity among onion cultivars of different origins was evaluated, in order to carry out genetic resources and breeding programs for this species on the Brazilian Northeast. Forty-one onion cultivars were analyzed for 146 polymorphic Pst $1 /$ Mse 1 AFLP bands, according to UPGMA phenogram, built with the Jaccard's similarity coefficient matrix. The phenogram co-phenetic value was estimated in 0.91 showing a good adequacy of the data. In the phenogram were observed two main onion groups at the cut point of 0.55 of similarity: 1) group composed of predominantly Brazilian cultivars, with some inclusion of foreigners; and 2) group with three foreign cultivars (Mercedes, Perfect and TEG 502 PRR). Rijnsburger Jumbo and IPA 8 presented the largest similarity ( $85 \%$ ), while Madrugada presented the greatest dissimilarity to the other cultivars. The cultivars developed by IPA were split in sub-groups within the group 1: IPA 8, IPA 10 and IPA 11; IPA 12, IPA 7, IPA 2 and IPA 6; IPA 3, IPA 4 and IPA 9 , suggesting that genetic variability could be explored by crosses among cultivars from different IPA subgroups. Bola Precoce and BRS Cascata presented the greatest similarity among the Brazilian cultivars. A similarity greater than $39 \%$ was observed, suggesting a high genetic variability of the analyzed onion collection. Introduction of new cultivars should take in consideration other origins than USA, in order to increase the genetic variability of onion germplasm in the Northeast Brazil.
\end{abstract}

Keywords: Allium cepa, cultivars, dissimilarity, Jaccard's coefficient, UPGMA.

(Recebido para publicação em 28 de maio de 2009; aceito em 25 de outubro de 2010) (Received on May 28, 2009; accepted on October 25, 2010)

\begin{abstract}
A cebola, Allium cepa L. $(2 \mathrm{n}=16)$, é originária das regiões de clima temperado que compreendem o Afeganistão, o Irã e partes do sul da antiga União Soviética. Tem sido cultivada por mais de 5.000 anos e, provavelmente, não existe mais em estado silvestre. As espécies mais próximas são $A$. galanthum e $A$. vavilovii, as quais podem ser encontradas em estado silvestres em áreas da antiga União Soviética e no Afeganistão (Goldman et al., 2000). Os europeus trouxeram a cebola para as Américas
\end{abstract}

logo no início do "descobrimento" e no século XIX a introduziram no leste da Ásia (Fritsch \& Friesen, 2002).

No Brasil, a cultura da cebola teve início no século XVIII no Rio Grande do Sul (municípios de Mostardas, Rio Grande e São José do Norte), introduzida pelos açorianos (Barbieri \& Medeiros, 2005). A partir de acessos de cebola introduzidos da Europa foram selecionadas duas populações principais: Baia Periforme no Rio Grande do Sul e Crioula em Santa Catarina (Buzar et al., 2007). No Nordeste brasileiro a cebola amarela foi introduzida no final da década de 1940, nas regiões de Cabrobó e Belém do São Francisco, sendo predominantemente produzida no Vale do São Francisco. Seleções locais como Roxa do Barreiro e Roxinha de Belém, esta última $A$. cepa var. aggregatum, já eram cultivadas na região (Costa et al., 1999).

As cultivares desenvolvidas pela Empresa Pernambucana de Pesquisa Agropecuária (IPA) ocupam quase 90\% 
do total da área cultivada com cebola na região do Vale do São Francisco (Pereira et al., 2000). Cultivares importadas do tipo "Grano" e híbridos tipo "Granex" são tradicionalmente cultivados no Nordeste e Sudeste do Brasil, sendo que no Nordeste dominaram o mercado até por volta de 1995. No Sul do Brasil predominam as cultivares dos tipos Baia Periforme e Crioula (Leite, 2005; Buzar et al., 2007).

Relações genéticas entre cultivares de cebola têm sido estabelecidas com marcadores moleculares dominantes, como RAPD (Leite et al., 2009), com marcadores moleculares codominantes, como microssatélites (Jakse et al., 2005; Mahajan et al., 2009) e com marcadores morfológicos e agronômicos (Barbieri et al., 2005; Buzar et al., 2007). Aplicação de marcadores dominantes tipo AFLP não tem sido relatada na literatura especializada, sendo que sua aplicação na cebola está restrita no desenvolvimento de mapas preliminares de ligações genéticas (Heusden et al., 2000) ou para o mapeamento de alelos do gene restaurador da fertilidade (Gokce et al., 2002). A técnica do AFLP tem sido também usada na análise da influencia da distância geográfica e altitude na divergência genética de três espécies de Allium silvestre no oeste norte americano (Phillips et al., 2008).

Apesar da dominância, o marcador AFLP é considerado uma poderosa ferramenta para análises de diversidade, devido à reprodutibilidade, à robustez, à geração de poucos artefatos e à ampla cobertura do genoma, apresentando resultados congruentes em várias situações com marcadores microssatélites (Meudt \& Clarke, 2007). Para Jaske et al., 2005) um dos problemas da aplicação de AFLP em cebola está relacionado com o grande número de bandas produzidas, em especial pela combinação das enzimas EcoR1 e Mse1, que não podem ser analisadas nos géis de poliacrilamida.

Este trabalho teve como objetivo estimar a similaridade genética, baseada em marcas de AFLP, entre cultivares de cebola de diferentes tipos e regiões geográficas, de forma a orientar programas de recursos genéticos e melhoramento da espécie para o Nordeste do Brasil.

\section{MATERIAL E MÉTODOS}

As 41 cultivares de cebola escolhidas para o presente estudo (Tabela 1) são parte da coleção de trabalho do programa de melhoramento de cebola da Embrapa Hortaliças e Semiárido. Além de originárias de regiões geográficas distintas, representam diferentes grupos agronômicos (Baia Periforme, Crioula, Pêra, Grano, Granex e Gladalan) e possuem qualidades agronômicas desejáveis para o melhoramento, bem como boa adaptação às condições de cultivo do Vale do Rio São Francisco.

O DNA total foi extraído de amostras foliares de cinco plantas em torno de 30 dias após a semeadura em PetrolinaPE, para constituir um 'bulk' de cada cultivar. A sementeira foi formada com 8 a $10 \mathrm{~g}$ de sementes $/ \mathrm{m}^{2}$, em sulcos transversais ao comprimento do canteiro. Foi incorporado $50 \mathrm{~g} / \mathrm{m}^{2}$ da mistura do adubo 6-24-12 antes da semeadura e uma complementação com adubação nitrogenada em cobertura, aos 20 dias após a semeadura, empregando-se 5 g de uréia/ $\mathrm{m}^{2}$. O protocolo para extração do DNA foi o CTAB 2x (Doyle \& Doyle, 1990), modificado para 6.000 e $13.000 \mathrm{rpm}$ na primeira e segunda centrifugação, respectivamente; beta-mercaptoetanol a $2 \%$ e incubação a $60^{\circ} \mathrm{C}$ durante 30 minutos para todas as amostras. Após a adição do tampão Tris-EDTA, a solução de DNA foi tratada com RNAse para remover RNAs co-isolados. A quantificação e a integridade do DNA foram verificadas em gel de agarose 0,8\%, seguido da diluição do DNA genômico para $50 \mathrm{ng} \mu \mathrm{L}^{-1}$.

Aproximadamente $200 \mathrm{ng}$ de DNA de cada cultivar foi duplamente digerido com 0,65 unidades das endonucleases Pst 1 e Mse1, por 2,5 horas em termociclador. A programação do termociclador para amplificações pré-seletivas consistiu de 20 ciclos a $94^{\circ} \mathrm{C}$ durante 30 segundos, $56^{\circ} \mathrm{C}$ durante 1 minuto e $72^{\circ} \mathrm{C}$ durante 1 minuto. Cada reação foi então diluída 20 vezes em tampão TE. Foram realizadas reações seletivas de amplificação para um volume final de $10 \mu \mathrm{L}$ de acordo com o protocolo: $0,2 \mu \mathrm{M}$ do inciador da PstI, 0,3 $\mu \mathrm{M}$ do iniciador da MseI, 0,2 mM de dNTPs, 1x tampão de PCR (100 mM Tris-HCl (pH
8,3), $500 \mathrm{mM} \mathrm{KCl}$ ), 2,5 mM de $\mathrm{MgCl}_{2}$, 0,5 unidades de Taq DNA Polimerase e $2 \mu \mathrm{L}$ do DNA pré-amplificado. A programação do termociclador para as amplificações seletivas consistiu de um ciclo a $94^{\circ} \mathrm{C}$, seguido de $65^{\circ} \mathrm{C}$ durante 30 segundos e de $72^{\circ} \mathrm{C}$ durante 1 minuto, repetidos 13 vezes e com a temperatura de anelamento de $65^{\circ} \mathrm{C}$ diminuindo de $0,7^{\circ} \mathrm{C}$ em todo ciclo subseqüente; 23 ciclos a $94^{\circ} \mathrm{C}$ por 30 segundos, $56^{\circ} \mathrm{C}$ durante 30 segundos e $72^{\circ} \mathrm{C}$ durante um minuto. As reações foram aquecidas durante 3 minutos a $94^{\circ} \mathrm{C}$ na presença de formamida e imediatamente colocadas sob gelo antes da aplicação nos géis de poliacrilamida. Os géis foram corados com nitrato de prata conforme Creste et al. (2001). Todas as reações foram conduzidas no laboratório de genética da Embrapa Semi-Árido.

Foram consideradas para análises apenas as cultivares que apresentaram número de falhas inferior a $10 \%$ do total de bandas polimórficas, como discutido por Warburton \& Crossa (2000). A partir dos dados de presença ou ausência de bandas foi construída a matriz de similaridade adotando-se o índice de Jaccard e confeccionado o fenograma pelo método de agrupamento UPGMA (Método de Agrupamento não Ponderado com base na Média Aritmética), disponível no programa NTSYS (Rohlf, 1989). A avaliação do ajuste do fenograma foi realizada pela correlação cofenética, ou seja, a correlação entre as distâncias reais e as representadas graficamente.

\section{RESULTADOS E DISCUSSÃO}

Foram obtidos 146 fragmentos polimórficos e 38 monomórficos em 13 combinações de primers (CP) EcoR 1/ Mse1 de AFLP, com média de 11,2 e 2,9 fragmentos polimórficos e monomórficos por $\mathrm{CP}$, respectivamente. As CPs produziram os seguintes números de bandas: GGG_CCC(11), GGA_CTG (11), GGG_CTC (14), GGA_CTG (9), GAT_CAC (9), GGG_CAC (15), GGA

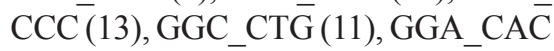
(12), GGG_CTG (11), GCT_CTG (12), GAT_CTG (7) e GCC_CĀG (11). A média de 15 fragmentos polimórficos de AFLP, com marcação com $\mathrm{P}^{33}$, foi relatada por Vos et al., 1995, a qual é 
Tabela 1. País de origem, tipo (polinização livre ou híbrida) e descendência de 41 cultivares de cebola avaliadas com marcadores AFLP (origin, type (open pollinated or hybrid) and descendent of 41 onion cultivars analysed with AFLP markers). Petrolina, Embrapa SemiÁrido, 2007.

\begin{tabular}{|c|c|c|c|}
\hline Populações & Origem & Tipo & Descendência \\
\hline Alfa São Francisco & Brasil & P. livre & Alfa Tropical $^{1}$ \\
\hline Alfa Tropical & Brasil & P. livre & Baia Periforme $^{2}$ \\
\hline Aurora & Brasil & P. livre & Baia Periforme $^{3}$ \\
\hline Baia Periforme Super Precoce & Brasil & P. livre & Baia Periforme $^{3}$ \\
\hline Beta Cristal & Brasil & P. livre & $\begin{array}{l}\text { Dehydrator } \mathrm{n}^{\circ} 2 \times \text { Dehydrator } \mathrm{n}^{0} 5 \mathrm{x} \text { Dehydrator } \mathrm{n}^{\circ} 8 \mathrm{x} \\
\text { Primero } \mathrm{x} \text { White Creole }\end{array}$ \\
\hline Bola Precoce ,(Empasc 352) & Brasil & P. livre & Baia Periforme $e^{10}$ \\
\hline BRS Cascata & Brasil & P. livre & Pêra Norte ${ }^{8}$ \\
\hline CNPH 6400 & Brasil & P. livre & Baia Periforme x Valcatorce INTA ${ }^{9}$ \\
\hline Conquista & Brasil & P. livre & Baia Periforme $^{3}$ \\
\hline Crioula Alto Vale (Epagri 362) & Brasil & P. livre & Crioula $^{10}$ \\
\hline Crioula Mercosul & Brasil & P. livre & Crioula $^{14}$ \\
\hline Excel & Itália & P. livre & Yellow Bermuda ${ }^{11}$ \\
\hline Henry's Special PRR & Estados Unidos & P. livre & Granex $^{12}$ \\
\hline IPA-10 & Brasil & P. livre & Roxa IPA-3 x Red Creole ${ }^{4}$ \\
\hline IPA-11 & Brasil & P. livre & Roxa IPA-3 x Belém IPA-94 \\
\hline IPA-12 & Brasil & P. livre & Roxa IPA-3 x Texas Grano $1015 \mathrm{Y}^{7}$ \\
\hline IPA-2 & Brasil & P. livre & Baia Periforme ${ }^{4}$ \\
\hline IPA-4 & Brasil & P. livre & Baia Periforme ${ }^{4}$ \\
\hline IPA-6 & Brasil & P. livre & Baia Periforme ${ }^{4}$ \\
\hline IPA-7 & Brasil & P. livre & Pêra Norte ${ }^{4}$ \\
\hline IPA-8 & Moçambique & P. livre & Mutuali $^{6}$ \\
\hline IPA-9 & Brasil & P. livre & Baia Periforme ${ }^{4}$ \\
\hline Jubileu & Brasil & P. livre & S. I. ${ }^{15}$, mas provavelmente de 'Pêra Norte' \\
\hline Madrugada & Brasil & P. livre & Baia Periforme ${ }^{3}$ \\
\hline Mayon & S. I. ${ }^{15}$ & P. livre & S. I. ${ }^{15}$ \\
\hline Mercedes & Estados Unidos & Híbrido & Granex $^{12}$ \\
\hline Norte 14 & Brasil & P. livre & Pêra Norte ${ }^{13}$ \\
\hline Optima & Austrália & Híbrido & Gladalan $^{14}$ \\
\hline Perfecta & Austrália & Híbrido & Gladalan $^{14}$ \\
\hline Pira Ouro & Brasil & P. livre & Baia Periforme $^{3}$ \\
\hline Primavera & Brasil & P. livre & Baia Periforme ${ }^{5}$ \\
\hline Régia & Brasil & P. livre & Gladalan $^{13}$ \\
\hline Rijnsburger Jumbo & Holanda & P. livre & S. I. ${ }^{15}$ \\
\hline Roxa 13 & Brasil & P. livre & Texas Grano ${ }^{9}$ \\
\hline Roxa do Barreiro & Brasil & P. livre & S. I. ${ }^{15}$ \\
\hline Roxa IPA-3 & Brasil & P. livre & Roxa do Barreiro ${ }^{4}$ \\
\hline São Paulo & Brasil & P. livre & Texas Grano $^{6}$ \\
\hline Serrana & Brasil & P. livre & Baia Periforme $^{3}$ \\
\hline TEG 502 & Estados Unidos & P. livre & Grano - Espanha ${ }^{11}$ \\
\hline TEG 502 PRR & Estados Unidos & P. livre & Texas Early Grano $502^{11}$ \\
\hline Yellow Granex & Estados Unidos & Híbrido & Granex $^{11}$ \\
\hline
\end{tabular}

${ }^{1}$ Costa et al. (2005); ${ }^{2}$ Araújo \& Rodrigues (1998); ${ }^{3}$ Melo \& Boiteux (2001); ${ }^{4}$ Costa et al. (1999); ${ }^{5}$ Garcia (1992); ${ }^{6}$ Pereira et al. (2000); ${ }^{7}$ Candeia et al. (2005); ${ }^{8}$ Choer (2005); ${ }^{9}$ Populações do programa de melhoramento genético da Embrapa; ${ }^{10} \mathrm{Gandin}(1995) ;{ }^{11} \mathrm{Goldman}$ et al . (2000); ${ }^{12}$ Currah (2002); ${ }^{13}$ Garcia (1987); ${ }^{14}$ Informações obtidas com as empresas detentoras das cultivares; ${ }^{15}$ Sem informações. 


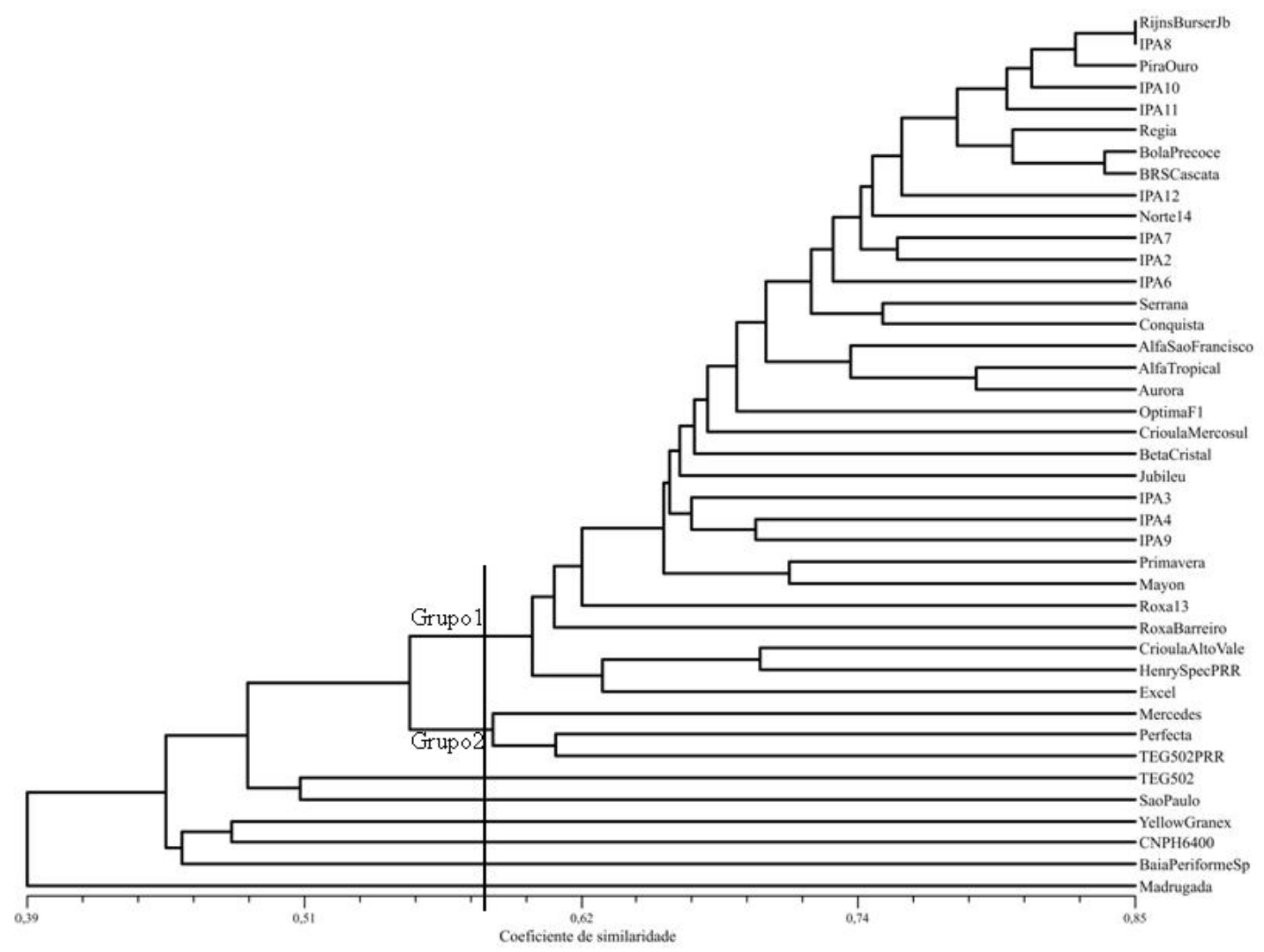

Figura 1. Fenograma UPGMA do coeficiente de similaridade de Jaccard de 41 cultivares de cebola, analisadas com 146 marcas de AFLP. Valor co-fenético $=0,91$ (UPGMA phenogram of the Jaccard's similarity coefficient of 41 onion cultivars, analyzed with 146 AFLP bands. Co-phenetic value $=0.91)$. Petrolina, Embrapa Semi-Árido, 2007.

próxima do valor obtido neste trabalho, usando coloração com nitrato de prata.

A correlação cofenética entre o procedimento SAHN com o coeficiente de similaridade da matriz de distâncias usando o procedimento MXCOMP do NTSYSpc (Rohlf, 1989) foi de 0,91, indicando que o fenograma produzido (Figura 1) representa adequadamente as reais distâncias estimadas com base nos 146 fragmentos de AFLP polimórficos.

Adotando-se o ponto de corte em torno de 0,55 de similaridade observa-se a formação de dois grupos principais, quais sejam: grupo 1) mais heterogêneo e formado por 32 cultivares (de Rijnsburger Jumbo até Excel), sendo 23 brasileiras obtidas de Baia Periforme, Pêra, Crioula e Roxa do Barreiro ou do cruzamento destas com outros acessos introduzidos; três cultivares brasileiras essencialmente derivadas de acessos introduzidos (Mutualli IPA 8, Régia e Beta Cristal) e três cultivares estrangeiras (Rijnsburger Jumbo, Optima F1 e Mayon); grupo 2) mais homogêneo e formado por três cultivares estrangeiras (Mercedes, Perfecta e TEG 502 PRR). Outras seis cultivares (Yelow Granex, São Paulo, CNPH 6400, TEG 502, Baia Periforme e Madrugada) ficaram alocadas sozinhas, sugerindo maior diversidade em relação às outras cultivares analisadas. A cultivar Madrugada, de origem brasileira, apresentou a maior dissimilaridade em relação ao conjunto de cultivares avaliado (Figura 1). Rijnsburger Jumbo, introduzida da Holanda, e IPA 8, derivada de Mutualli e introduzida da África (Tabela 1), foram as mais similares (85\%) do fenograma.

As cultivares da série IPA, adaptadas às condições de clima e solo do Vale do Rio São Francisco, se dividiram em três subgrupos no grupo das cultivares brasileiras: IPA 8, IPA 10 e IPA 11; IPA 12, IPA 7, IPA 2 e IPA 6; IPA 3, IPA 4 e IPA 9 (Figura 1), indicando que embora haja estreito relacionamento entre as 'IPAs' situadas dentro do mesmo subgrupo, há suficiente variabilidade genética a ser explorada entre aquelas situadas em subgrupos distintos. À exceção de IPA 3, IPA 7, IPA 8, IPA 10 e IPA 12, as demais 'IPAs' são derivadas de Baia Periforme (Tabela 1).

As cultivares Alfa Tropical e Alfa São Francisco, no grupo das cultivares brasileiras, posicionaram em ramos imediatos no fenograma (Figura 1) refletindo o relacionamento próximo, pois a Alfa São Francisco é derivada da Alfa Tropical (Tabela 1). Norte 14 e IPA 7, esta derivada de Norte 14 (Tabela 1), também posicionaram-se próximas no fenograma, indicando que a seleção 
em Norte 14 em condições de cultivo nas latitudes $8-9^{\circ}$, ou seja, sob condições de dias curtos e calor constante predominantes na região do Vale do São Francisco, não foi suficiente para proporcionar elevada dissimilaridade entre as cultivares.

Bola Precoce, uma cultivar do tipo Baia Periforme (Gandin, 1995) exibiu similaridade de $82 \%$ com BRS Cascata, do tipo Pêra, sendo essa similaridade a maior observada entre as cultivares brasileiras. A cultivar Crioula Mercosul, do tipo Crioula e as cultivares do tipo Pêra (BRS Cascata, Norte 14, IPA 7 e Jubileu) posicionaram-se próximas das cultivares de Baia Periforme, indicando a origem comum dos três tipos de cebola predominantes no Brasil, originalmente introduzidas pelos açorianos no Rio Grande do Sul (Buzar et al., 2007). A exceção foi Crioula Alto Vale, também do tipo Crioula, que no presente estudo exibiu maior proximidade com as cultivares suaves e precoces provenientes dos Estados Unidos (Figura 1).

O grupo formado por Mercedes, Perfecta e TEG 502 PRR, no ponto de corte de 0,55 de similaridade, reflete um nível considerável de relacionamento entre elas, pois ambas são do tipo Grano. TEG 502 e TEG 502 PRR, embora posicionadas em ramos imediatos no fenograma, exibiram dissimilaridade maior que o esperado, indicando que as diferenças genéticas entre ambas possivelmente vão além da resistência a Pyrenochaeta terrestris, causador da raiz rosada, presente da TEG 502 PRR e ausente em TEG 502.

As cultivares revelaram similaridade superior a 39\% (Figura 1), o que reflete a alta variabilidade genética da coleção de germoplasma de cebola estudada (Tabela 1). Ampla variabilidade também foi observada por Buzar et al. (2007) entre acessos de cebola avaliados com base em caracteres fenotípicos.

Os dois principais grupos formados refletem a origem das cultivares avaliadas: 1) grupo formado predominantemente por cultivares brasileiras, com origem na população 'Garrafal' introduzida pelos açorianos, que originou a Baia Periforme, enquanto Pêra Norte foi, provavelmente, introduzida do Norte da África (Barbieri \& Me- deiros, 2005); 2) grupo formado por cultivares introduzidas dos Estados Unidos da América, principalmente, que têm origem em introduções do tipo Grano realizadas da Espanha em 1925, tendo 'Valenciana' como a população base (Goldman et al., 2000). Estudos com microssatélites ou marcadores de regiões conservadas de DNA dos cloroplastos devem ser realizados para elucidar resultados não esperados como o relativo distanciamento entre Régia, Optima F1 e Perfecta, todas do tipo Gladalan e a pequena similaridade entre Baia Periforme Super Precoce e, principalmente, de Madrugada com as demais populações de Baia Periforme (Figura 1).

Considerando as condições de cultivo do Vale do Rio São Francisco, para a obtenção de cultivares divergentes e com bom desempenho agronômico e/ ou para a formação de híbridos com boas expressões de heterose sugere-se cruzamentos entre as cultivares Alfa São Francisco ou IPA 11 ou IPA12 com cultivares do outro grupo, como TEG 502 PRR ou São Paulo, pois as mesmas formaram grupos distintos no fenograma (Figura 1). Recomenda-se, ainda, que introduções de novas cultivares devam considerar aspectos agronômicos específicos, como tolerância às doenças predominantes na região, ou procedências outras que não os Estados Unidos da América, de forma a aumentar a variabilidade de germoplasma de cebola disponível no Brasil.

\section{AGRADECIMENTOS}

Ao BNB-Etene-Fundeci-Banco do Nordeste do Brasil e CNPq, pelo financiamento da pesquisa.

\section{REFERÊNCIAS}

ARAÚJO MT; RODRIGUES AG. 1998. Alfa Tropical: nova cultivar de cebola de verão. In. CONGRESSO BRASILEIRO DE OLERICULTURA, 38. Resumos... Petrolina: SOB (CD-ROM).

BARBIERI RL; MEDEIROS ARM. 2005. A cebola ao longo da história. In: BARBIERI, RL (ed). Cebola: ciência, arte e evolução. Brasília: Embrapa Informação Tecnológica, V. 1, p. 13-20.

BARBIERI RL; LEITE DL; CHOER E;
SINIGAGLIA, C. 2005. Divergência genética entre populações de cebola com base em marcadores morfológicos. Ciência Rural 35: 303-308.

BUZAR AGR.; OLIVEIRA VR; BOITEUX LS. 2007. Estimativa da diversidade genética de germoplasma de cebola via descritores morfológicos, agronômicos e bioquímicos. Horticultura Brasileira 25: 527-532.

CANDEIA JA; LIMA MMA; LEMOS MCS; MENEZES JT; COSTA ND; MENEZES D; SANTOS CAF. 2005. Brisa IPA-12: Cultivar de cebola suave. In: CONGRESSO BRASILEIRO DE OLERICULTURA, 45. Resumos ... Fortaleza: SOB (CD-ROM).

CHOER E. 2005. Variabilidade genética em cebola. In. BARBIERI RL (ed). Cebola: ciência, arte e história. Brasília: Embrapa Informação Tecnológica, v. 1, p. 73-78.

COSTA ND; CANDEIA JA; ARAÚJO MT. 1999. Importância econômica da cebola no Nordeste. In: QUEIROZ MA; GOEDERT CO; RAMOS SRR (eds). Recursos Genéticos e Melhoramento de Plantas para o Nordeste Brasileiro. Disponível em HTTP://www. cpatsa.embrapa.br/catpub. Acessado em 15 de fevereiro de 2009.

COSTA ND; SANTOS CAF; QUEIROZ MA; ARAÚJO HM; OLIVEIRA, VR; MENDONÇA, JL; CANDEIA, JA. 2005. Alfa São Francisco: variedade de cebola para cultivo no verão. In: CONGRESSO BRASILEIRO DE OLERICULTURA, 45. Resumos ... Fortaleza: SOB (CD-ROM).

CRESTE S; TULMANN NETO A; FIGUEIRA A. 2001. Detection of single sequence repeat polymorphisms in denaturing polyacrilamide sequencing gels by silver staining. Plant Molecular Biology Reporter 19: 299-306.

CURRAH L. 2002. Onions in the tropics: cultivars and country reports. In: RABINOWITCH HD; CURRAHL (eds). Allium Crop Science: Recent Advances. Wallingford: CAB International. p. 379-407.

DOYLE JJ; DOYLE JL. 1990. Isolation of plant DNA from fresh tissue. Focus 12: 13-15.

FRITSCH RM; FRIESEN N. 2002. Evolution, Domestication, and Taxonomy. In: RABINOWITCH HD; CURRAH L (eds). Allium Crop Science: Recent Advances. Wallingford: CAB International. p. 5-30.

GANDIN CL. 1995. Cultivares. In: ENCONTRO TÉCNICO SOBRE SISTEMA DE PRODUÇÃO DE SEMENTES DE CEBOLA EM SANTA CATARINA, 1. 1993, Ituporanga. Anais. Ituporanga: Epagri/Estação Experimental de Ituporanga, p. 25-30.

GARCIA A. 1992. Cultivar Primavera: cebola para colheita em épocas de melhores preços. HortiSul 2: 32-37.

GARCIA A. 1987. Cultivares. In: AMARAL AS; GARCIA A; CASTRO C; STUMPF CL; MORAES EC; MADAIL JCM; DYNIA JF; BICCALHF; CARVALHO RPL (eds). Cultura da cebola para sementes no Rio Grande do Sul. Pelotas: EMBRAPA-CNPFT. p. 14-16.

GOKCE AF; MCCALLUM J; SATO Y; HAVEY MJ. 2002. Molecular tagging of the Ms locus in onion. Journal of American Society for Horticulture Science 127: 576-582. 
GOLDMAN IL; HAVEY MJ; SCHROECK G. 2000. History of public onion breeding programs and pedigree of public onion germplasm releases in the United States. Plant Breeding Reviews 20: 67-103.

HEUSDEN AW; OOIJEN JW; GINKEL V.; VERBEEK WHJ; WIETSMA WA; KIK C. 2000. A genetic map of an interspecific cross in Allium based on amplified fragment length polymorphism (AFLPTM) markers. Theoretical and Applied Genetics 100: 118126.

JAKSE J; MARTIN W; McCALLUM J; HAVEY MJ. 2005. Single nucleotide polymorphisms, indels, and simple sequence repeats for onion cultivar identification. Journal of the American Society for Horticulture Science 130: 912-917.

MAHAJAN V; JAKSE J; HAVEY MJ; LAWANDE KE. 2009. Genetic fingerprinting of onion cultivars using SSR markers. Indian Journal of Horticulture 66: 62-68.
LEITE DL. 2005. Melhoramento genético de cebola. In: BARBIERI RL (ed). Cebola: ciência, arte e evolução. Brasília: Embrapa Informação Tecnológica, v. 1, p. 81-118.

LEITE DL; ANTHONISEN D; BARBIERI RL. 2009. Divergência genética entre acessos do banco ativo de germoplasma de cebola da Embrapa Clima Temperado revelada por marcadores RAPD. Pelotas: Embrapa Clima Temperado, 2009. 7 p. (Embrapa Clima Temperado. Boletim de pesquisa e desenvolvimento, 81).

MELO PCT; BOITEUX LS. 2001. Análise retrospectiva do melhoramento genético de cebola (Allium cepa L.) no Brasil e potencial aplicação de novas estratégias biotecnológicas. In: CONGRESSO BRASILEIRO DE MELHORAMENTO DE PLANTAS, 1. Resumos ... Goiânia: SBMP (CD-ROM).

MEUDT HM; CLARKE AC. 2007. Almost Forgotten or Latest Practice? AFLP applications, analyses and advances. Trends in Plant Science 12: 107-117.

PEREIRAW; VIEIRAJV; MENDONÇAJL. 2000. Relatório do Workshop sobre cebolicultura no Brasil. Brasília: EMBRAPA-CNPH. 76 p. Embrapa Hortaliças. Documentos, 25.

PHILLIPS NC; LARSON SR; DROST DT. 2008. Detection of genetic variation in wild populations of three Allium species using amplified fragment length polymorphisms. HortScience 43: 637-643.

ROHLF FJ. 1989. NTSYS-pc numerical taxonomy and multivariate analysis system, version 1.80. Setauket: Exeter Software.

VOS P; HOGERS R; BLEEKER M; REIJANS M; DER LEE T; HORNES M; FRIJTERS A; POT J; PELEMAN J; KUPIER M; ZABEAU M. 1995. AFLP: A new technique for DNA fingerprinting. Nucleic Acids Research 23: 4407-4414.

WARBURTON M; CROSSA J. 2000. Data analysis in the CIMMYT applied biotechnology center for fingerprinting and genetic diversity studies. Mexico, D.F.: CIMMYT. 23 p. 